\title{
Experimental and Numerical Study on Ultimate Strength of Steel Tubular Members with Pitting Corrosion Damage
}

Renhua Wang ${ }^{1 * *}$, R Ajit Shenoi².

wrhchina@163.com

1. Department of Civil Engineering, Jiangsu University of Science of Technology, Zhenjiang 212003, China

2. Southampton Marine and Maritime Institute, University of Southampton, Boldrewood Innovation Campus, Southampton SO16 7QF, UK

\begin{abstract}
Pitting corrosion can cause stress concentration and early onset of plasticity in the metallic structural components. This paper presents a comprehensive experimental and numerical study on the effect of pitting features such as pit shape and depth, pitting distribution and intensity on the structural performance of steel tubular members. The experimental investigations were carried out on tubular members with mechanically drilled pitting damage under axially loaded compression condition. The test results were applied to validate finite element (FE) models by comparing the load-shortening curves, ultimate loads and failure modes. The validated FE models were then used to simulate the random nature of pitting damage in terms of stochastic simulation. The results from the stochastic analyses show that random natures associated with pit shape, pit depth and pitting distribution can result in a great reduction and variation of ultimate strength, likely causing the transition of collapse mode. The experiments provide a modelling benchmark to validate FE models of the tubular structures with random pitting corrosion for the ultimate strength assessment. The developed FE models are shown to be capable of replicating the pitted tubular members.
\end{abstract}

Keywords: steel tubular member; pitting corrosion; compressive column test; ultimate load; FE modelling; stochastic simulation 


\section{Introduction}

Tubular members are widely used in structures in oil, nuclear, hydroelectric, and petrochemical industries [1-3]. These structural members can be subject to localised pitting corrosion, which is the cause of a potentially destructive damage in metallic structures $[4,5]$. Pitting corrosion is a form of extremely localized attack to the mass of metal due to the corrosive medium, leading to the creation of small pits or holes in the metal. The resulting pits become wide and shallow or narrow and deep which can potentially perforate the wall thickness of a metal. It is essential to assess the impact of such pitting corrosion damage accurately for monitoring, damage mitigation and life extension of such members [6-8]. A comprehensive review in this area [9] indicated that the structural behaviour due to pitting features such as pit depth, pit density and interfacial distances between pits is still not fully understood.

Experimental and numerical studies were performed to understand the behaviour of tubular members with artificially introduced localized pitting or patch-type corrosion, which are applied in steel lined pipes $[10,11]$ and tubular members for offshore structures [12, 13]. Recent experimental research into the effect of pitting corrosion artificially drilled on the local region of tubular members for offshore platforms [14] showed that aside from the compressive strength, pitting corrosion affects the structural failure mode in the pattern of local buckling. Studies on stiffened plated structures showed that pitting damage has an impact on failure patterns and leads to a decrease in structural strength $[15,16]$. Many studies have been performed on the degradation of material property of steel tensile specimens $[17,18]$ and the strength reduction of plate structures [19-22]. It is still however challenging to model pitting damage [5], using the less precise inspection data of corrosion that comes from the representative regions of aged structures. As a result, assessing the current fitness of the structures with pitting damage can only be based on simplified methods of equivalent thickness or elastic modulus. Yielding of cross-section and global buckling of an entire member may occur if only simplified methods are used [23]. Importantly, information 
about pitting effect on the overall strength of tubular members remains insufficient as is evident from some recent literature [24-26].

In this paper, compressive loading tests on the tubular members with artificial pitting damage were carried out to study the effect of diverse pitting features on the structural strength and deformation, presenting a benchmark experiment used to validate numerical studies. FE models, validated against test results, were used to replicate the tested members subject to artificial pitting damage. This was followed by modelling random pitting for structural ultimate strength assessment, involving generation of pseudo random pitting damages. The variation of ultimate strength and the mechanism of structural failure, which are derived from the localized and widespread random pitting damages, were explored through comparing the FE results between various pitting damages, based on stochastic simulation.

\section{Experimental method}

An experimental programme was devised to investigate the structural strength and behaviour of tubular members subjected to simulated pitting corrosion. The tested members were made from a seamless circular steel tubular member with an external diameter of $54 \mathrm{~mm}$, thickness of $6.9 \mathrm{~mm}$ ( $D / t$ ratio of 7.83), and length of $460 \mathrm{~mm}$. Pitting was artificially introduced into the members by mechanical drilling, with variations in pit shape, pit depth, pitting intensity and distribution pattern. Overall, the experimental programme included two material tensile coupon tests and 14 member tests under compressive loads.

\subsection{Tested members}

All pits in the tested members were formed mechanically as circular or pyramidal cavities. This was achieved by using two kinds of drill bits, both of a diameter of $6 \mathrm{~mm}$, but one with a flat crown and the other with a $1 \mathrm{~mm}$ high pyramidal crown. Two types of pitting patterns mechanically simulated as shown in Figure 1 were introduced into the test members. Details of the pitting patterns in the different tubular test specimens are reported in Table 1. The degree of pitting 
intensity (DOP) is used to represent the lost area in the members due to pitting corrosion in comparison with an intact member and is defined as:

$$
D O P=\frac{A_{c}}{A_{0}} \times 100(\%)=\frac{\sum_{i=1}^{N} \pi r_{i}^{2}}{A_{0}} \times 100(\%)
$$

The degree of volume loss (DOV) of lost, corroded material is defined as:

$$
D O V=\frac{V_{c}}{V_{0}} \times 100(\%)=\frac{\sum_{i=1}^{N} \pi r_{i}^{2} d_{i}}{V_{0}} \times 100(\%)
$$

where $A_{0}$ and $V_{0}$ are the area and volume of the intact member respectively, and $A_{c}$ and $V_{c}$ denote the lost area and volume due to pitting corrosion respectively. $N$ is the number of pits, and $r_{i}$ and $d_{i}$ are respectively the radius and depth of the $i^{\text {th }}$ pit.

Every member was labelled, based on its pitting condition. A label of INTACT stands for the basic tubular member without pitting and is regarded as a reference for strength reduction of the pitted members. The first letter "U” or "I" in the member label indicates pitting distribution scattered in uniform or interleaved pattern. The second letter of " $\mathrm{C}$ " or " $\mathrm{P}$ " indicates whether a pit is circular or pyramidal in its shape. The four numbers following the two front letters stand for the number of pits in the length and hoop directions, and the numbers following "d" for pit depth. For example, IC2010d4.9 means that 200 circular pits (20 in the length direction and 10 in the hoop direction) with a depth of $4.9 \mathrm{~mm}$ are distributed on the member surface, where pits are staggered. Similarly, UP2410d5.1 represents 240 pyramidal pits (24 in the length direction and 10 in the hoop direction) with a depth of $5.1 \mathrm{~mm}$; the pits are uniformly distributed on the member and the pits in two contiguous lines are completely aligned. The DOP of every member was estimated, depending on the mean value of radius and depth of the measured pits. The dimensions of 12 pits, situated radially and along the member length, were measured by a Vernier calliper. The diameters of all the drilled pits were equal to the diameter of the drill bit, $6 \mathrm{~mm}$. Figure 2 reports the measured depths of all the artificial pits for each tested member, showing the maximum, minimum and mean values. 
All the tested members were made from the same steel pipe of grade China GB8162-2008 20 carbon steel. The material property of the tested members was determined by tensile coupon tests, using a CMT5105 testing machine. An extensometer mounted on the coupon was used to determine the elongation of each coupon over a $50 \mathrm{~mm}$ gauge length. The stress-strain characteristics of the two tensile specimen tests are shown in Figure 3. Young's modulus, E, was 125 GPa, as derived from the stress-strain curve in the elastic deformation region. Yield stress, $\sigma_{y}$ and ultimate stress, $\sigma_{u}$ were $311 \mathrm{MPa}$ and $463 \mathrm{MPa}$, respectively. Possion’s ratio was assumed to be 0.3.

\subsection{Test setup and procedure}

Compressive loading tests were conducted, using a YNS-1000 kN servo electro-hydraulic universal testing machine with circular rigid platens at both ends. Figure 4 shows a photograph and schematic representation of loading test setup. The bottom end platen was used as a fixed support platform for the tested member, while the top end platen served as a loading actuator. Every tested member was welded to $10 \mathrm{~mm}$ thick endplates at both ends and then was bolted to two flat plates of $12 \mathrm{~mm}$ thickness, termed in Figure 4, as wedge connectors, before being mounted on the testing machine between the two end platens.

A small alignment load of $5 \mathrm{kN}$ was applied before the compressive loading test started. This was done to ensure full contact between the end platens, wedge connectors and tested member. The loading test was then performed through a displacement control method at a constant speed of 1.5 $\mathrm{mm} / \mathrm{min}$. The loading process progressed until the tested member collapsed, with the maximum loading displacement of $30 \mathrm{~mm}$. Due to the difficulty in forecasting the deforming direction of the tested member under compression, only the axial deformation was measured. Real-time loaddisplacement curve of the tested member was recorded in the testing system. 


\section{Experimental analysis}

\subsection{Effect of pitting features}

Table 2 reports the key experimental results including ultimate load, $F_{u}$, and the corresponding axial displacement, $\Delta_{u}$. Two reference values, $F_{r e f}$ and $\Delta_{r e f}$, are the load and corresponding axial displacement of the intact member at ultimate state respectively. These two latter values are used to calculate the percentage of degradation of the ultimate load and deforming resistance of the pitted members. Typical collapse modes of the tested members are shown in Figure 5. Some typical experimental results of load shortening curves are shown in Figure 6.

In order to study the effect of a pitting feature under various circumstances, every basic group was reclassified into two or three subgroups. Comparison of the effect of the pitting feature was conducted between the reclassified tested members within each basic group, and the compared results are reported in Table 3.

\subsubsection{Effect of pit shape}

In the basic group of SHAPE in Table 3, strength reductions caused by circular and pyramidal pits were compared under different pit depths for the same level of pitting intensity, DOP 9.97\%, resulting from 240 uniformly distributed pits. The pyramidal pit was drilled using a drilling bit with a $1 \mathrm{~mm}$ high pyramidal crown while the drill bit used to form the circular pit had a flat crown. For the same drill bit height in both pyramidal and circular cases, it is clear that volume loss in the pyramidal drill bit case is less than that in the circular drill bit case. This decrement in the volume loss for the pyramidal case is approximated to a $1 \mathrm{~mm}$ discount in pit depth. Therefore, in subgroup SHAPE-A, the tubular member with pyramidal pit (UP2410d3.6) has a higher compressive strength than that with circular pit (UC2410d3.8), since the pyramidal pit results in a smaller pit depth of about $2.6 \mathrm{~mm}$. However, in subgroup SHAPE-B, the tubular members with pyramidal and circular pits have nearly equal compressive loads because of almost the same volume loss of material in 
UP2410d5.1 and UC2410d3.9. Pit shape thus has negligible influence on the strength decrease of the pitted tubular member, when pitting damage causes the same volume loss of material.

\subsubsection{Effect of pit depth}

Comparison of pit depth on strength reduction was performed under three levels of pitting intensities, DOPs 6.65\% (DEPTH-A), 8.31\% (DEPTH-B) and 9.97\% (DEPTH-C), in Table 3. It is seen that strength decreases with increase in the pit depth at the same level of pitting intensity. However, the magnitude of strength reduction is different under different pitting intensities. Deeper pits in the subgroups of DEPTH-A, with the minimum DOP 6.65\%, and DEPTH-C, with the maximum DOP 9.97\%, result in a larger magnitude of strength decreases than that in DEPTH-B with a medium DOP $8.31 \%$. Thus, pit depth plays a vital role to reduce the ultimate strength of the pitted tubular member as concerned in the regulations for fitness assessment [5].

\subsubsection{Effect of pitting intensity}

The effect of pitting intensity on the compressive strength of the pitted tubular member was investigated under various pit depths, as reported in Table 3. In subgroup DOP-A, under the same pit depth of $2.8 \mathrm{~mm}$, a higher DOP 8.31\% in UC2010d2.8 leads to a larger strength reduction than the lower DOP 6.65\% in UC2008d2.8. However, in DOP-B, a higher DOP 8.31\% in UC2010d4.8 causes a lower strength reduction than that in the lower DOP 6.65\% in UC2008d5.3. Additionally, in DOP-C, a higher DOP 12.46\% in UC3010d3.4 results in the almost same strength reduction as in the case of the lower DOP 9.97\% in UC2410d3.8. The disparities in the effect of pitting intensity show that the higher DOP does not always result in a larger strength reduction than the lower one. In those cases with the higher DOP but smaller pit depth, such as DOP-B and C, the effect of higher DOP may be counterbalanced by a smaller pit depth as its effect is less impactful on the strength reduction than the pit depth. 


\subsubsection{Effect of pitting distribution pattern}

Comparison of the effect of pitting distribution pattern on the strength reduction was performed between interleaved and uniform pitting patterns under different pit depths and pitting intensities in the basic group PATTERN, as shown in Table 3. A slight variation of $0.1 \mathrm{~mm}$ due to the machining error arises in the measured pit depths of the compared members within each subgroup. However, this is considered to be of little importance as it did not cause obvious variance in the test strength. In PATTERN-A with DOP 8.31\%, the strength reduction derived from the interleaved pitting pattern in IC2010d2.9 is quite close to that caused by the uniform pattern in UC2010d2.8. A similar trend is also shown in PATTERN-B. However, in PATTERN-C with a relatively higher DOP $12.46 \%$, the strength reduction for the interleaved pattern is more than that for the uniform one. The effect of pitting distribution pattern on the strength reduction thus appears to be associated with the pitting intensity.

\subsection{Result summary}

Comparisons between the pitted member and intact member in Table 2 clearly show that more the pitting corrosion, and thus material loss, the greater structural strength reduction. The impact of pitting on the ultimate axial deformation is, however, more complex. The deforming resistances in most of the tested members exhibit a decreasing trend in strength as the pitting damage becomes more severe, except for UC3010d3.4, UC2410d3.9 and UP2410d5.1 which show slightly improved deforming resistances. This disparity in the ultimate deformation arises under higher level of pitting intensities. This latter set of results needs further study both through experimental confirmation as well as through numerical modelling.

With respect to the load shortening curves, Figure 6 shows an almost coincident tendency in members UC2010d4.8, UC3010d3.4 and UP2410d5.1 despite the reduction in the overall structural stiffness. This means that pit depth is more detrimental to ultimate strength and can offset the effect of pitting intensity. One striking example is that a lower DOP 9.97\% in UC2410d6.9 rather than the 
higher DOP $12.46 \%$ in UC3010d3.4 results in the lowest compressive strength. This also suggests that pitting damage is best characterized by the maximum pit depth albeit in consideration with the material area, in a Level 1 Assessment [5]. ASTM G46-96 [27] elaborates the methods often used in situ for measuring the pit depth in terms of visual and other non-destructive inspection techniques using pit gauge, ultrasonic and radiographic techniques etc. However, the determination of pit depth remains a great challenge because none of these non-destructive techniques can provide satisfactory detailed information about pitting damage [9]. Notably, even if more precise measures are available to detect pit depth, it seems impractical to simulate pitting damage precisely as in-situ pitting. This is due to the difficulties in modelling random nature of pitting damage and trans-scale between the small pit and large structure. It is desirable if to overcome the difficulties through addressing pitting details with fine finite element meshes. But it most likely result in a new problem that the fine mesh model might lead to an unacceptable consumption of computing resource. Therefore, modelling the probabilistic feature of the measured pit depth is vital for the structural integrity assessment [28].

Pitting corrosion can be commonly represented by the density, size and depth of corrosion pits. The measure of pitting damage is performed in terms of a visual comparison between the actual pitting of a component and the standard pit charts in the API Specification [5]. This can identify a pit chart to indicate the degree of pitting intensity (DOP) that approximately rates the density of the corrosion pits of the metal component in need of inspection. Statistical information is then derived from a typical region chosen by the inspector to represent the actual damage condition of the entire pitted component. This information derived includes the pit number, the mean and maximum depths and diameters of the measured pits. However, these datum are not exact but statistical for depicting the actual pitting corrosion, expressing a descriptive statistic of pit depths likely subject to a normal, lognormal or any other probability distribution [29]. One of those probabilistic models well fit to the statistical feature of the measured pit depths can be used, in conjunction with these statistical datum, to define the degree of volume loss (DOV) of corroded material in terms of a stochastic 
simulation [30]. In fact, the DOV is increasingly accepted for ultimate strength assessment of the pitted structure because it can involve the integrated effect of pitting features associated with the pit depth and pitting intensity on the strength decrease [31, 32]. Meanwhile, pit shape, on its own, has little influence in the strength reduction. The volume loss is then employed to describe the law of strength reduction in the tubular member due to the pitting corrosion, as shown in Figure 7. A high correlation between the DOV and strength reduction shows the suitability of the method based on the volume loss to predict the strength decrease in some extent.

It is worth noting that the artificial pitting in the experimental studies has one major limitation to depict the real pitting damage. This relates to the pitting intensities involved in the test where only limited levels of pitting intensities and limited forms of pitting patterns were considered [5]. In particular, both the interleaved and uniform pitting patterns are in essence two forms of regularly distributed pitting damages. Actual pitting corrosion has more randomness in the pit shape, pit depth and pitting distribution, as well as a larger variation in the pitting intensity. The combined effect on the strength reduction of these can be explored by numerical modelling.

\section{Numerical analysis}

A numerical modelling programme was carried out using the nonlinear FE analysis package ANSYS. The FE models were firstly validated against the reported experimental results, and then utilized to expand the numerical study onto the effect of random pitting damage on the structural performance of the tubular member. The FE model validation focused on the ultimate loads, loaddeformation curves and failure modes derived from the numerical analysis and experiments. The random natures of the pitting damage were incorporated into the developed FE models by random variables concerning pit shape and depth, as well as pitting distribution.

Previous studies into the structural behaviour of tubular member show that although initial global geometric imperfection was measured using a theodolite, a global deflection of one thousandth member length can provide better agreement for the numerical analysis against the 
experimental results [33]. For the member welded by manual welding, residual stress is altered by various factors [34], inevitably causing extra initial deflection besides that resulting from the manufacturing process of the seamless pipe. One thousandth of the effective member length was thereby used for the initial deflections of all the tested members throughout the numerical studies. The initial imperfection was related to the factors such as: the residual stress derived from the hand welding; local distortions owing to test sample manufacture; and the difficulty to measure the geometric deflection on the uneven pitted surface.

\subsection{Modelling information}

Modelling the tubular members with pitting damage employed a four-node shell element with reduced integration, SHELL181 in ANSYS package, with quadrilateral meshes. A uniform mesh of size $t \times t$ was applied in the regions of the member surface without pits, but more intensive meshes were used for modelling pitting detail. All the pits were modelled as cylindrical holes regardless of the difference of pit shape. The depth of a pyramidal pit was $1 \mathrm{~mm}$ lesser than that of a cylindrical one on the basis that it approximated the lesser volume lost in the former case under the same drilled depth. Meshing pattern for the detailed pit involved two schemes, namely a fine mesh with 16 shell elements and a coarse mesh with 8 shell elements surrounding one pit, as shown in Figure 9. With respect to the fine mesh scheme, one pit was described by 48 quadrilateral shell elements; in the coarse mesh case, one pit was described by only 12 shell elements. The meshes in the regions away from the pits were altered correspondingly with the variation of the mesh density in the pitting region for the fine and coarse meshes, due to their shared boundaries.

In consideration of the random nature of pitting damage, structural symmetry was discarded in all FE models. All degrees of freedom of nodes on the loaded end of the member were coupled to a concentric node in the centroid of cross section, which served as a reference node for applying compressive load and was only allowed to move along the longitudinal axis of the member. All the nodes at the support end were constrained to simulate the fixed-ended boundary condition. A 
loading displacement of $30 \mathrm{~mm}$ was gradually applied to the reference node to implement loading process resembling the compressive loading test.

The measured engineering material stress and strain were converted into the true stress and logarithmic strain for input into ANSYS, according to Eqs. (3) and (4),

$$
\begin{aligned}
& \sigma_{\text {ture }}=\sigma(1+\varepsilon) \\
& \varepsilon_{\ln }=\ln (1+\varepsilon)
\end{aligned}
$$

where $\sigma$ and $\varepsilon$ are the measured stress and strain obtained from tensile coupon tests respectively, while $\sigma_{\text {true }}$ and $\varepsilon_{\ln }$ are the true stress and logarithmic strain respectively.

The applied material curves input in the numerical modelling is shown in Figure 8. In terms of initial geometric imperfection, a cosine wave shape was employed [23], defined as:

$$
w(x)=w_{m}\left[\cos \left(\frac{2 \pi}{L} x\right)-1\right]
$$

where $w_{m}$ is the maximum deflection at the mid-length of member with $1 / 1000$ of the effective length, $L$, of member, and $x$ is the location of a certain section in longitudinal direction of the member. Geometrical and material nonlinearities were considered in the FE analysis.

\subsection{Validation of numerical models}

Validation of the numerical models, with coarse and fine meshes, was carried out by benchmarking the FEA results against the experimental ones. Figure 9 displays the comparisons of

the ultimate loads obtained by the FE analyses and experimental tests as well as their relative errors. The results show that fine mesh models provide more accurate ultimate load, without consuming too much extra computing resource. The fine mesh model was thereby adopted for the remainder sensitivity studies. Figure 10 shows the full load shortening curves of the typical numerical results and their experimental counterparts, showing very good matches. The failure modes of the FE models show excellent agreement with those derived from the tests s, as shown in Figure 11. The developed FE model is therefore able to predict the ultimate loads, load-deformation behaviours, and failure modes of the tubular members subject to pitting corrosion. 


\subsection{Structural performance under pseudo random pitting damages}

Actual pitting corrosion has a more complex randomness in contrast to the artificial pitting damage that was mechanically drilled in the tested members. The tested member was further used to explore the effect of the randomness in pitting corrosion. The measured pit depth and diameter in the tested member of UC3010d3.4 with a relatively higher pitting intensity were adapted into pseudo random pitting damages in the form of localized pitting or widespread pitting. A simple random number method was applied to model the random nature, related to the pit shape, pit depth and pitting distribution, in the random pitting corrosion. The pit depths of 300 simulated pits randomly varied in the range of $[0.8,6.8] \mathrm{mm}$ resulting in an average depth of $3.4 \mathrm{~mm}$, equal to the measured mean depths. The diameters of the simulated pits varied in the range of $[1.8,13.2] \mathrm{mm}$ with a uniform distribution, resulting in a mean diameter of $6 \mathrm{~mm}$ equal to the size of the drilled pits. Three random variables were applied to reflect all the random natures in pitting damage. The simulated pit depths in the FE models were considered close to the corrosion data collected from mild steel specimens with pit depths that follows a normal distribution with mean value of $3 \mathrm{~mm}$ and standard deviation of $0.5 \mathrm{~mm}$ [29]. The pit shapes reflected by the randomly variant diameters were also consistent with the ratio of pit diameter to depth in the range of [8:1, 10:1] as recorded for marine structure [35].

A series of FE analyses were carried out to clarify statistical characteristics of the ultimate strength and adverse impact of the random pitting damage on the structural behaviour.

\subsubsection{Localized pitting corrosion}

Figure 12 illustrates the results of the intact member and locally pitted members, showing the load shortening curves and collapse mode at ultimate state. In the pitted member, all 300 pits had constant shape and depth with $6 \mathrm{~mm}$ diameter and $3.4 \mathrm{~mm}$ depth, respectively, randomly scattered on the local region in the middle or one end of the member. The localized pitting damage results in an obvious discrepancy in the load shortening curves in the post-collapse stage due to the change in 
the location of pitting distribution, as shown in Figure 12. The ultimate load for the intact member is $354 \mathrm{kN}$; ultimate load for the member with pitting concentrated in the middle part is $321 \mathrm{kN}$; and ultimate load for the member with pitting concentrated in one end is $311 \mathrm{kN}$. The simulated pitting situated close to the support end thereby leads to a strength reduction, of about $12.1 \%$ compared with the intact member, larger than that located in the middle part.

\subsubsection{Measured pitting corrosion}

Recalling the measured data of the pit depths in UC3010d3.4 showed maximum, minimum and mean values of $3.9 \mathrm{~mm}, 3.1 \mathrm{~mm}$ and $3.4 \mathrm{~m}$, respectively, as shown in Figure 2. The random nature of the measured pit depth was simulated, ranging from $0.8 \mathrm{~mm}$ to $6.8 \mathrm{~mm}$ through a simple random number method, which resulted in an average pit depth of $3.4 \mathrm{~mm}$, i.e. equal to the mean value of the measured pit depth. The diameters of those random pits were a constant of $6 \mathrm{~mm}$, resulting in pitting degradation of DOV 6.18\%. All the pits were randomly allocated on the member surface in numerical models. Stochastic analysis was performed on 200 FE models, each of which represented a different pitting distribution pattern. This was done to explore the statistical characteristics of the compressive strengths of the pitted member.

Figure 13 reports the statistical properties of ultimate loads for 200 FE models. The ultimate strength of the tubular member under DOV 6.18\% has a mean value of $323 \mathrm{kN}$ and a standard deviation (Stdev) of $2.046 \mathrm{kN}$, due to the change in the pitting distribution of the measured pitting. While the ultimate strength seemingly complies with a normal distribution. The relative error of the mean value against the tested result $(327 \mathrm{kN})$ is about $1.2 \%$. The worst pitting scenario leading to the lowest strength results in a strength degradation about 3.3\% more than the corresponding test result. In respect to collapse mode, the FE models with the measured (limited random) pitting and regular (uniform) pitting duplicating the tested member achieve a similar collapse mode, as shown in Figure 14(a), which is featured by a global buckling same as that for the tested member shown in 
Figure 5(right). Hence the limited random nature of pitting damage due to the mechanical drilling has a minimal impact on the ultimate strength and does not affect the structural failure mode.

\subsubsection{Random pitting corrosion}

A pseudo random pitting was employed to explore the effect of the random nature in the pitting corrosion damage. The random number method was applied in the construction of FE model. The random pitting features involving the pit shape, pit depth and pitting distribution were all taken into account. The statistical properties of the pit diameter and depth of the pseudo random pitting were consistent with the measured data in the tested member. The simulated randomness were reflected by the pit diameter ranging from $1.8 \mathrm{~mm}$ to $13.2 \mathrm{~mm}$, equal to the average diameter of $6 \mathrm{~mm}$, and the pit depth ranging from $0.8 \mathrm{~mm}$ to $6.8 \mathrm{~mm}$, equal to the average depth of $3.4 \mathrm{~mm}$. The pitting corrosion with such statistical features leaded to the degree of pitting degradation of DOV 7.59\%. Stochastic analysis accounting for the variation of pitting distribution was also carried out on the 200 FE models.

Figure 15 illustrates the statistical properties of the ultimate strength of the member with the random pitting damage. The mean $(310 \mathrm{kN})$ and minimum $(260 \mathrm{kN})$ values of the ultimate strength are respectively less than the test strength $(327 \mathrm{kN})$ with about $5.2 \%$ and $20.5 \%$. It is evident that the random pitting results in a larger strength reduction compared with the measured more regular pitting in the experiment. It also causes more significant variation in the ultimate strength. Notably, in the worst case, an adverse pitting distribution of the random pitting leads to the structural failure due to a local buckling but not the global buckling, as shown in Figure 14(b). Figure 14(c) shows that the material yielding prior to the local buckling arises from the high stress concentration due to two pits with relatively larger diameters situated on the side of the maximum compressive fiber of the member. This results in the failure mode transition as found in the plated structures [15]. The adverse impact of the random pitting damage deserves further exploration under different corrosion scenarios. 


\subsubsection{Various levels of pitting intensities}

Stochastic analysis was performed on $1000 \mathrm{FE}$ models for variant pitting situations, which covered a larger range of levels of pitting degradations within DOVs [0, 9]\%, in order to study the correlation of the reduction of ultimate strength with the level of pitting degradation thoroughly. Figure 16 displays the results of these stochastic analyses together with the results of the 14 tested members and 400 models simulated in the previous two Sections 4.3.2 and 4.3.3, showing the relationship of ultimate loads of the pitted members with the volume loss of material. The variation of the ultimate load, besides a significant decrease, becomes more serious with increase of the level of pitting degradation.

Due to the simplification in the pitting morphology, treating the random pitting as that with a regular shape, depth and distribution, the member tests tend to provide unduly optimistic results of the ultimate strengths, as shown in Figure 16. In contrast, the prediction in terms of the FE models can cover all the results of the member tests with regular pitting damage, except for that with perforated pits due to its unconventionality for the in-service structures [5]. Hence, the developed FE model herein is able to take the place of the expensive member test with artificial regular pitting. On the other hand, since modelling random pitting as a regular one underestimates the reduction of ultimate strength as reported in the experiments, which only concern a specified regular or irregular pitting distribution, and the same pitting shape and depth, it may lead to a high risk in the structural safety.

Comparisons of the collected results between the measured pitting and the random pitting in Figure 16 show that the effect of pitting damage on the structural strength is highly related to the expression of pitting corrosion model. The different expression results in a great disparity in the volume loss of corroded material even if under the same statistical properties. For example, the measured pitting and random pitting lead to DOV 6.18\% and DOV 7.59\% respectively, although both models have the same mean values of pitting size and depth. Consequently, a more serious 
strength reduction, besides a clearly wider spectrum of strength variation, is caused by the random pitting, as shown in Figure 16. Actually, the progress of corrosion depths of pits varies over time with a different probabilistic distribution [9, 35]. The probabilistic expression of the random pitting corrosion deserves more concern in the future research into the ultimate strength assessment of the pitted structures.

These illustrative initial sets of simulations provide a base for a next set of further studies examining the effects of variabilities on reliability of corroded tubular specimens under external loads. Further experimental studies on the randomly pitted tubular member are in progress. In our further studies, the repeatability of the experiments deserves more attention to isolate the strength scatter of experimental error and that resulting from the randomness of pitting damage.

\section{Conclusion}

This paper presents a comprehensive experimental and numerical study on the structural performance of steel tubular members subject to pitting corrosion under compression. The test setup, experimental procedures, ultimate loads, load-deformation curves and failure modes are fully reported. Experimental analyses on diverse pitting features under various corrosion scenarios were conducted to explore the effects of pitting features on strength degradation. This clearly showed the importance of pitting features such as pit shape and depth, pitting intensity and distribution pattern to cause a strength decrease. Pitting damage degrades the ultimate strength significantly, and reduces the ultimate deforming capability for most of the tested members. Pit depth proved more detrimental to the ultimate strength than pitting intensity, while volume loss of material loss represents the main effect of pitting damage to impact on the strength decrease. The developed FE models proved suitable to reflect the test results including the ultimate strength, load-deformation relationship and failure mode, and to replicate the member subject to random pitting damage. Random pitting corrosion was shown to have more significant impact on the structural strength and behaviour than the more regular pitting introduced in the experimentally tested members. 


\section{Acknowledgements}

This work was supported by Natural Science Foundation of Jiangsu Province of China [grant number BK20151326], Natural Science Foundation of China [grant number 51879124], and the sponsorship of Jiangsu Overseas Research \& Training Program for University Prominent Young \& Middle-aged Teachers and Presidents (2016). The first author gratefully appreciated these supports.

\section{Reference}

[1] Khedmati MR, Nazari M. A numerical investigation into strength and deformation characteristics of preloaded tubular members under lateral impact loads. Marine Structures. 2012;25:33-57.

[2] Monsalve-Giraldo JS, Giraldo-Londoño O, Colorado-Urrea GJ, Dantas CMS, Aristizabal-Ochoa JD. Second-order analysis of an imperfect corroded tubular member on a two-parameter elastic foundation. Eng Struct. 2017;137:223-35.

[3] Wang X, Melchers RE. Long-term under-deposit pitting corrosion of carbon steel pipes. Ocean Eng. 2017;133:23143.

[4] Caines S, Khan F, Shirokoff J. Analysis of pitting corrosion on steel under insulation in marine environments. J Loss Prevent Proc. 2013;26:1466-83.

[5] API/ASME. API 579-1/ASME FFS-1 Fitness-For-Service. 2016.

[6] Tan C, Lu Y, Zhang X. Life extension and repair decision-making of ageing offshore platforms based on DHGF method. Ocean Eng. 2016;117:238-45.

[7] Zeinoddini M, Ranjbar P, Khalili H, Ranaei A, Golpour H, Fakheri J. Remaining fatigue life assessment of aging fixed steel offshore jacket platforms. Structure and Infrastructure Engineering. 2016;12:223-38.

[8] Vanaei HR, Eslami A, Egbewande A. A review on pipeline corrosion, in-line inspection (ILI), and corrosion growth rate models. Int J Pres Ves Pip. 2017;149:43-54.

[9] Bhandari J, Khan F, Abbassi R, Garaniya V, Ojeda R. Modelling of pitting corrosion in marine and offshore steel structures - A technical review. J Loss Prevent Proc. 2015;37:39-62.

[10] Dewanbabee H, Das S. Structural behavior of corroded steel pipes subject to axial compression and internal pressure: Experimental study. J Struct Eng. 2013;139:57-65.

[11] Mohd MH, Lee BJ, Cui Y, Paik JK. Residual strength of corroded subsea pipelines subject to combined internal pressure and bending moment. Ships and Offshore Structures. 2015;10:554-64.

[12] Hebor ME, Rieles JM. Local buckling strength of patch corrosion damaged steel tubular bracing. International Journal of Steel Structures. 2002;2:59-70.

[13] Nazaria M, Khedmati MR, Khalaj AF. A numerical investigation into ultimate strength and buckling behavior of locally corroded steel tubular members. Latin American Journal of Solids and Structures. 2014;11:1063-76.

[14] Ahn J-H, Choi WR, Jeon SH, Kim S-H, Kim I-T. Residual compressive strength of inclined steel tubular members with local corrosion. Appl Ocean Res. 2016;59:498-509.

[15] Amlashi HKK, Moan T. On the strength assessment of pitted stiffened plates under biaxial compression loading. ASME 24th International Conference on Offshore Mechanics and Arctic Engineering. Halkidiki, Greece2005. p. 83-92. 
[16] Sultana S, Wang Y, Sobey AJ, Wharton JA, Shenoi RA. Influence of corrosion on the ultimate compressive strength of steel plates and stiffened panels. Thin Wall Struct. 2015;96:95-104.

[17] Nakai T, Matsushita H, Yamamoto N, Arai H. Effect of pitting corrosion on local strength of hold frames of bulk carriers (1st report). Marine Structures. 2004;17:403-32.

[18] Sheng J, Xia J. Effect of simulated pitting corrosion on the tensile properties of steel. Constr Build Mater. 2017;131:90-100.

[19] Paik JK, Lee JM, Ko MJ. Ultimate compressive strength of plate elements with pit corrosion wastage. Journal of Engineering for the Maritime Environment. 2003;217:185-200.

[20] Nakai T, Matsushita H, Yamamoto N. Effect of pitting corrosion on local strength of hold frames of bulk carriers (2nd Report) - Lateral-distortional buckling and local face buckling. Marine Structures. 2004;17:612-41.

[21] Nakai T, Matsushita H, Yamamoto N. Effect of pitting corrosion on strength of web plates subjected to patch loading. Thin Wall Struct. 2006;44:10-9.

[22] Zhang Y, Huang Y, Wei Y. Ultimate strength experiment of hull structural plate with pitting corrosion damage under unaxial compression. Ocean Eng. 2017;130:103-14.

[23] Lutes LD, Kohutek TL, Ellison BK, Konen KF. Assessing the compressive strength of corroded tubular members. Appl Ocean Res. 2001;23:263-8.

[24] Yamane M, Tanaka K, Matsuda B, Fujikubo M, Yanagihara D, Iwao N. Residual strength evaluation of corroded steel members in marine environments. 16th International Offshore and Polar Engineering Conference. San Francisco, California, USA: International Society of Offshore and Polar Engineers; 2006.

[25] ISO19902. Petroleum and natural gas industries - Fixed steel offshore structures. 2007.

[26] Wang Y, Wharton JA, Shenoi RA. Ultimate strength analysis of aged steel-plated structures exposed to marine corrosion damage: A review. Corros Sci. 2014;86:42-60.

[27] ASTM G46-94. Standard guide for examination and evaluation of pitting corrosion. 2013.

[28] Wang R, Ajit Shenoi R, Sobey A. Ultimate strength assessment of plated steel structures with random pitting corrosion damage. J Constr Steel Res. 2018;143:331-42.

[29] Melchers RE. Statistical characterization of pitting corrosion - Part 2: Probabilistic modeling for maximum pit depth. Corrosion. 2005;61:766-77.

[30] Daidola JC, Parente J, Orisamolu IR, Ma KT. Residual strength assessment of pitted plate panels. Washington, D.C.: U.S. Coast Guard (G-MMS/SSC); 1997.

[31] Jiang X, Guedes Soares C. Ultimate capacity of rectangular plates with partial depth pits under uniaxial loads. Marine Structures. 2012;26:27-41.

[32] Zhang Y, Huang Y, Zhang Q, Liu G. Ultimate strength of hull structural plate with pitting corrosion damnification under combined loading. Ocean Eng. 2016;116:273-85.

[33] Zhao O, Gardner L, Young B. Testing and numerical modelling of austenitic stainless steel CHS beam-columns. Eng Struct. 2016;111:263-74.

[34] Silva CC, Farias JP. Non-uniformity of residual stress profiles in butt-welded pipes in manual arc welding. J Mater Process Tech. 2008;199:452-5.

[35] Yamamoto N. Probabilistic model of pitting corrosion and the simulation of pitted corroded condition. ASME 27th International Conference on Offshore Mechanics and Arctic Engineering. Estoril, Portugal2008. p. 527-34. 



\section{List of Figures and Tables}

Figure 1 Typical tested steel tubular members with uniformly and crosswise distributed pits

Figure 2 Measured pit depths of tested members

Figure 3 Stress-strain relation of tested members

Figure 4 Schematic diagram of experimental setup

Figure 5 Failure modes of typical tested members

Figure 6 Load shortening curves of typical tested members

Figure 7 Ultimate strength reduction versus corroded volume loss

Figure 8 Stress-strain relationship of tested members applied in numerical analysis

Figure 9 Comparison between numerical and experimental results

Figure 10 Load shortening curves of typical experimental and corresponding numerical results

Figure 11 Failure mode of typical experimental and numerical results

Figure 12 Load shortening curves and collapse modes of tubular members with localized pitting damage

Figure 13 Frequency of ultimate strengths of tubular members subject to measured pitting damage

Figure 14 Collapse modes of tubular members subject to pitting damage

Figure 15 Frequency of ultimate strengths of tubular members subject to random pitting damage

Figure 16 Comparison of ultimate loads between experimental and FE results

Table 1 Pitting damage in tested members

Table 2 Summary of experimental results of pitted members

Table 3 Comparison of pitting effect on strength reduction 


\section{Figures}

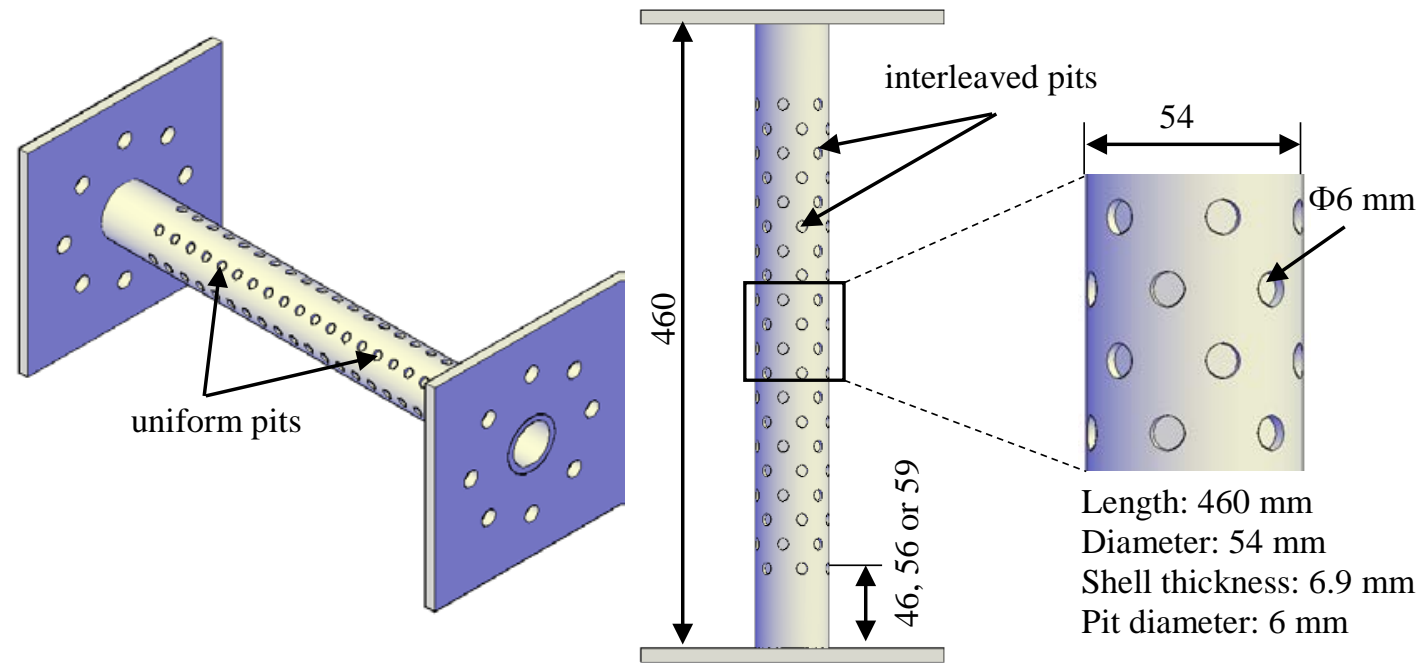

Figure 1 Typical tested steel tubular members with uniformly and crosswise distributed pits

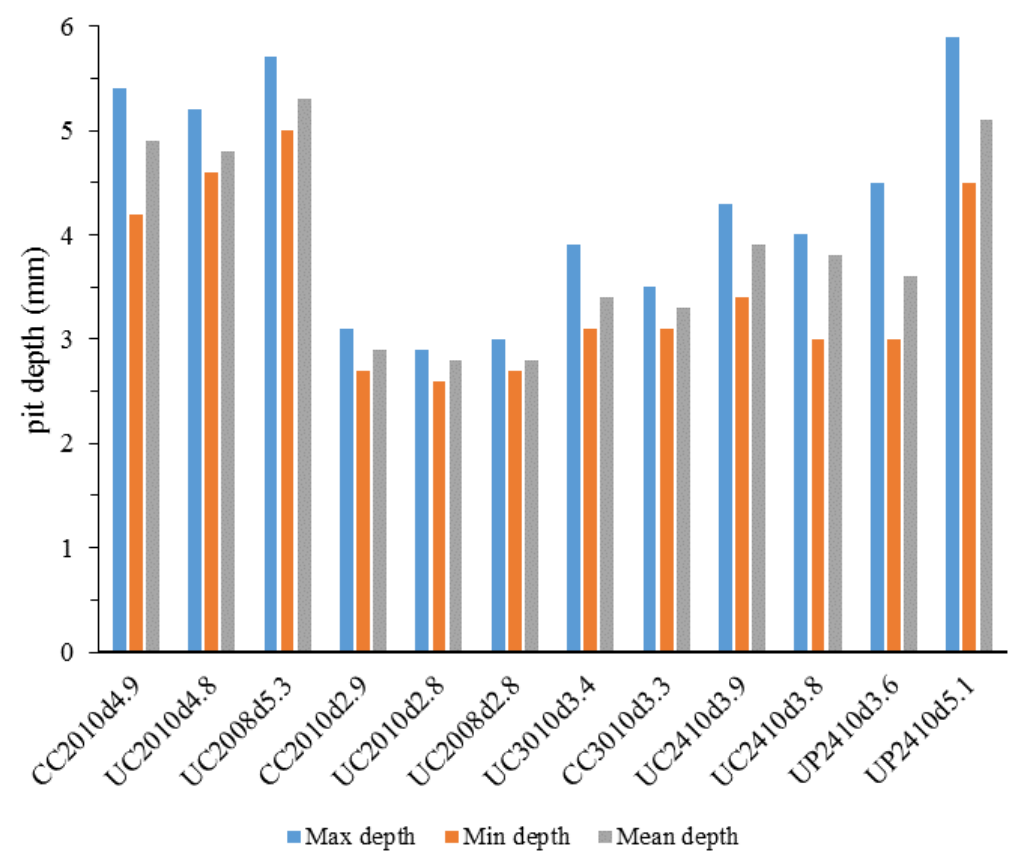

Figure 2 Measured pit depths of tested members 


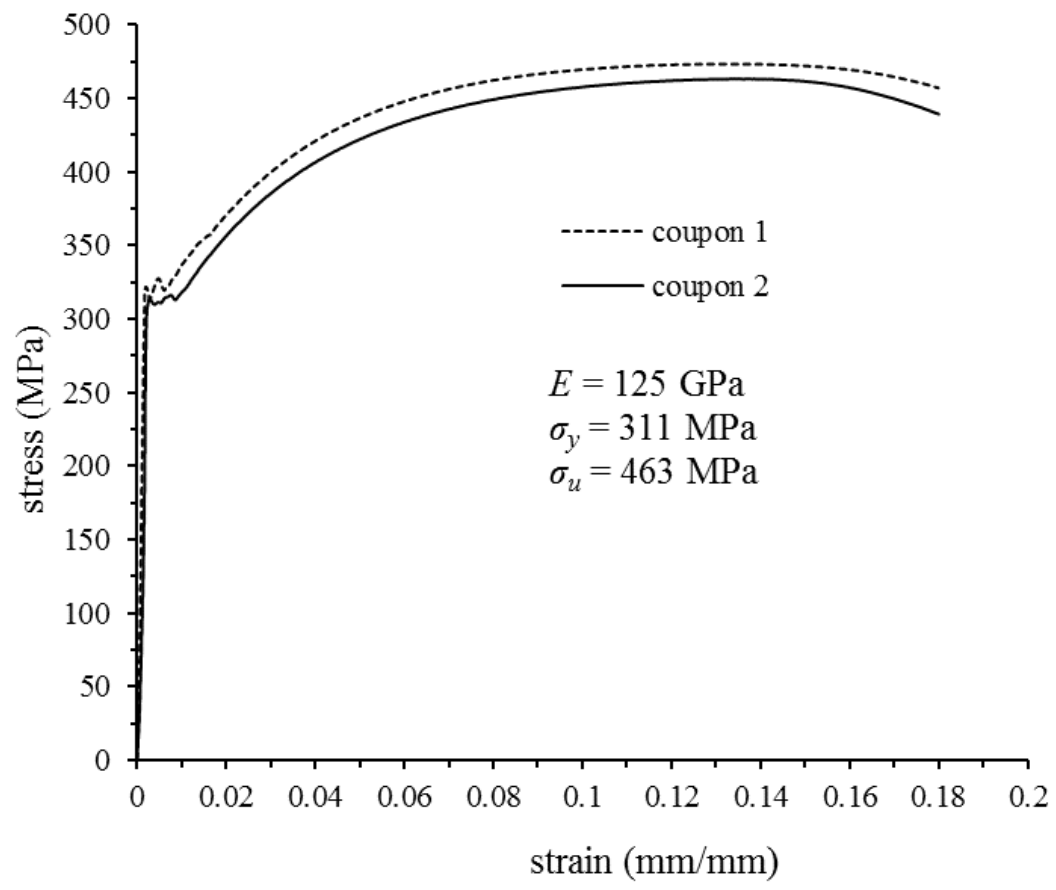

Figure 3 Stress-strain relations of tensile specimens of tested members

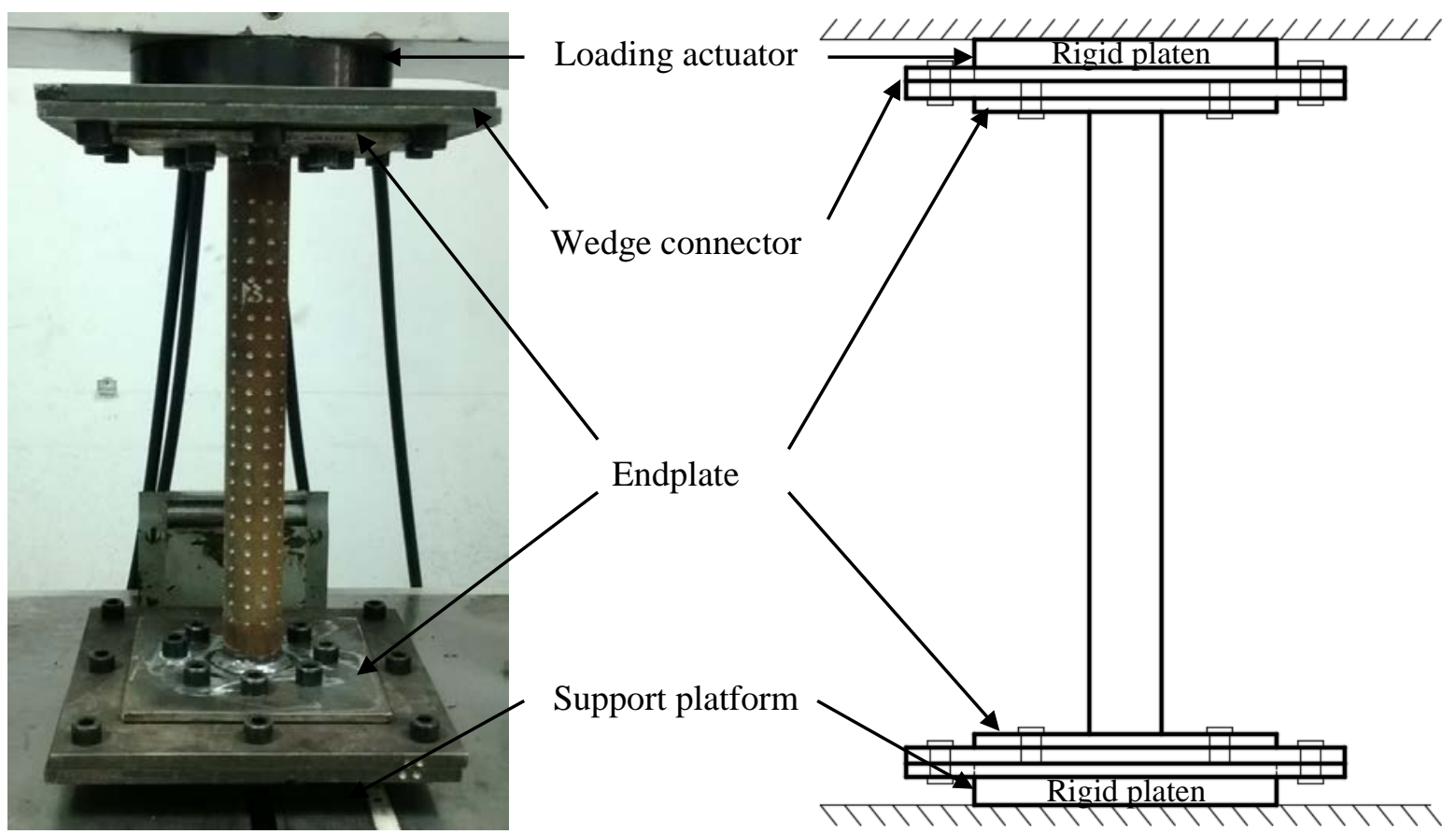

Figure 4 Schematic diagram of experimental setup 

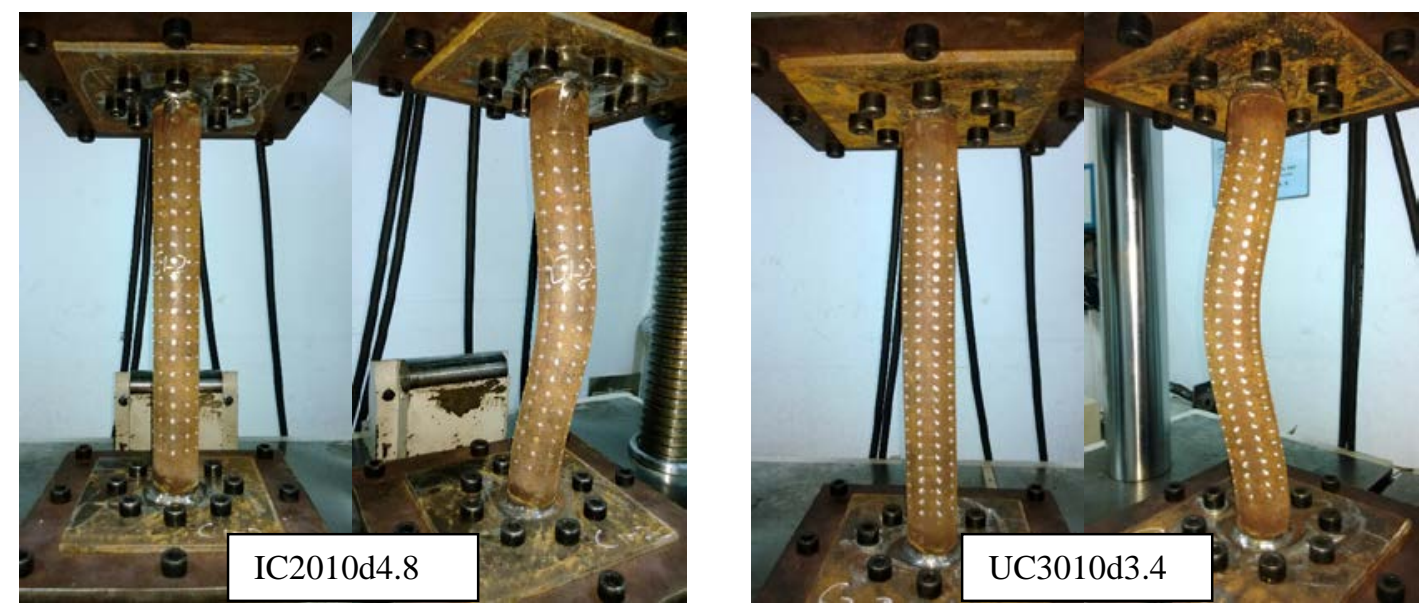

Figure 5 Failure modes of typical tested members

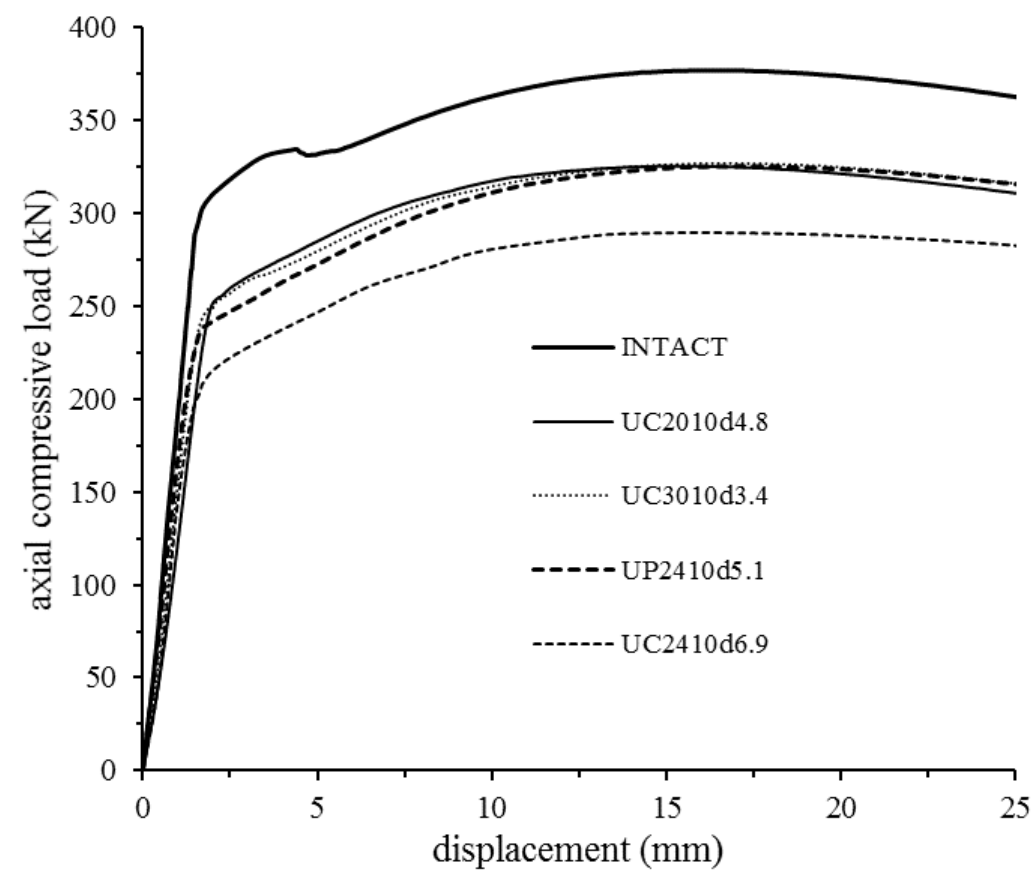

Figure 6 Load shortening curves of typical tested members 


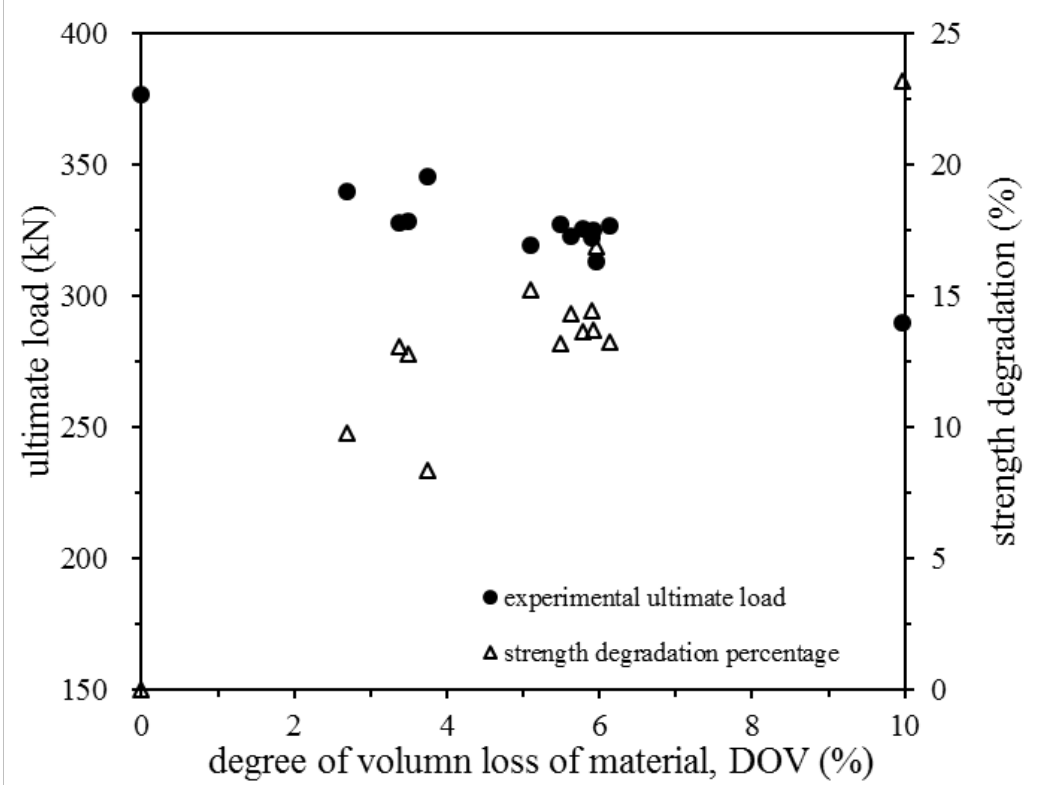

Figure 7 Ultimate strength reduction versus corroded volume loss

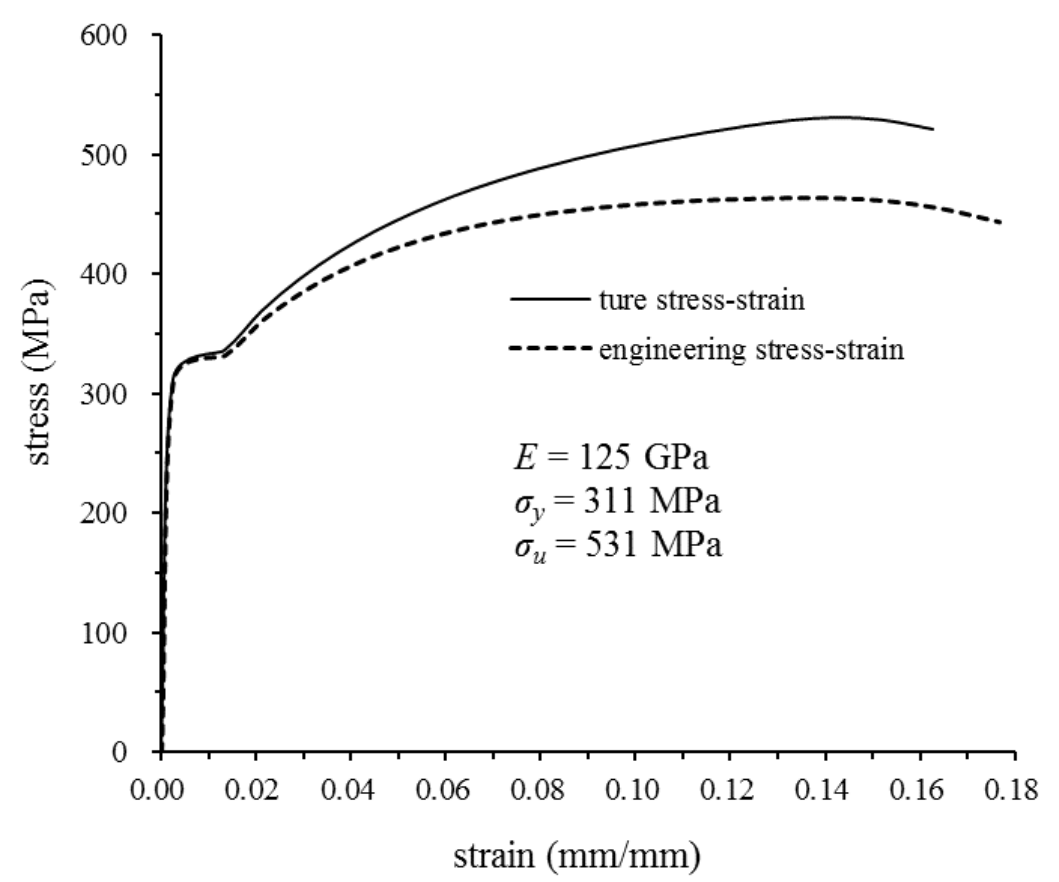

Figure 8 Stress-strain relationship of tested members applied in numerical analysis 


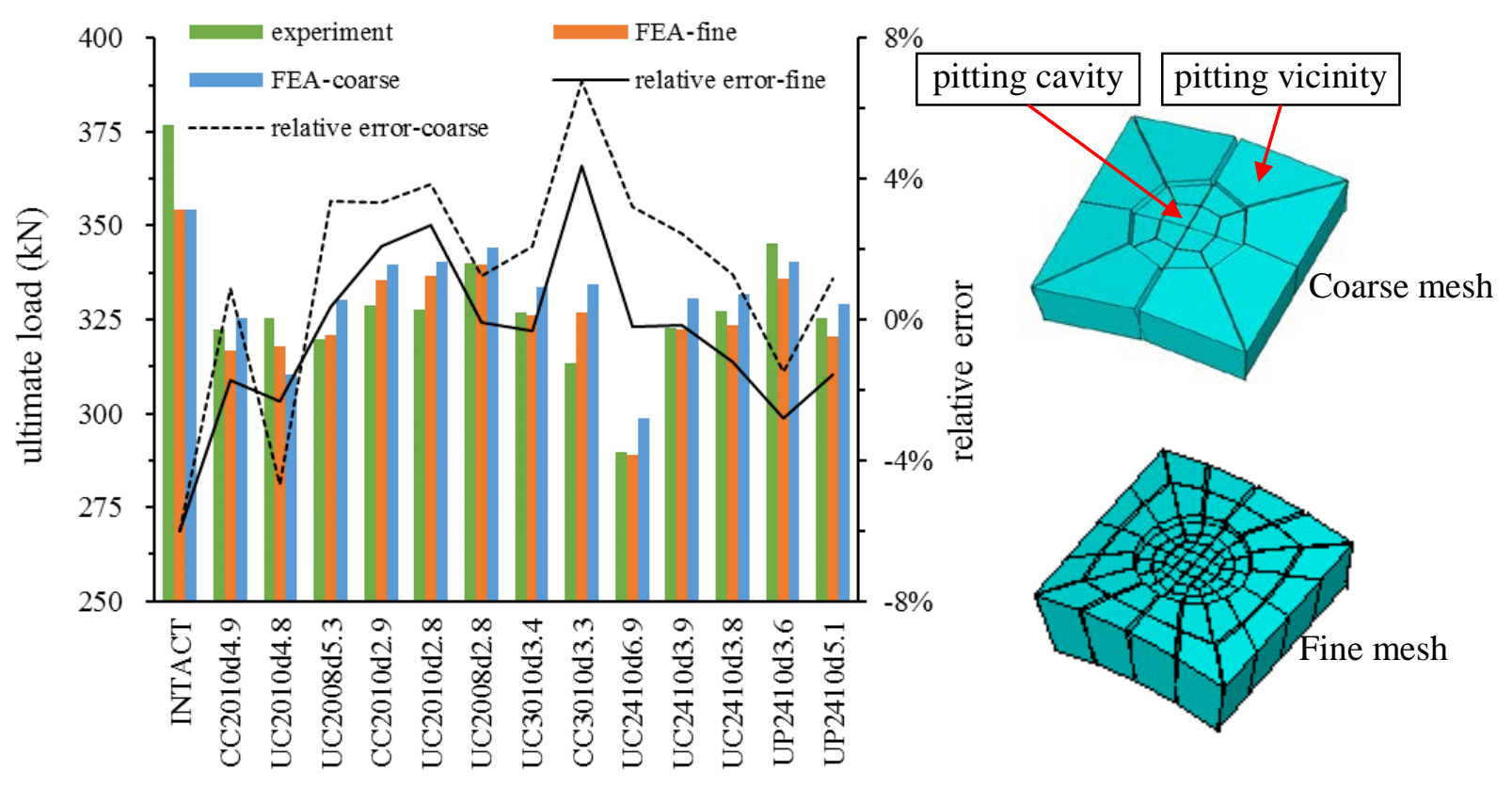

Figure 9 Comparison between numerical and experimental results

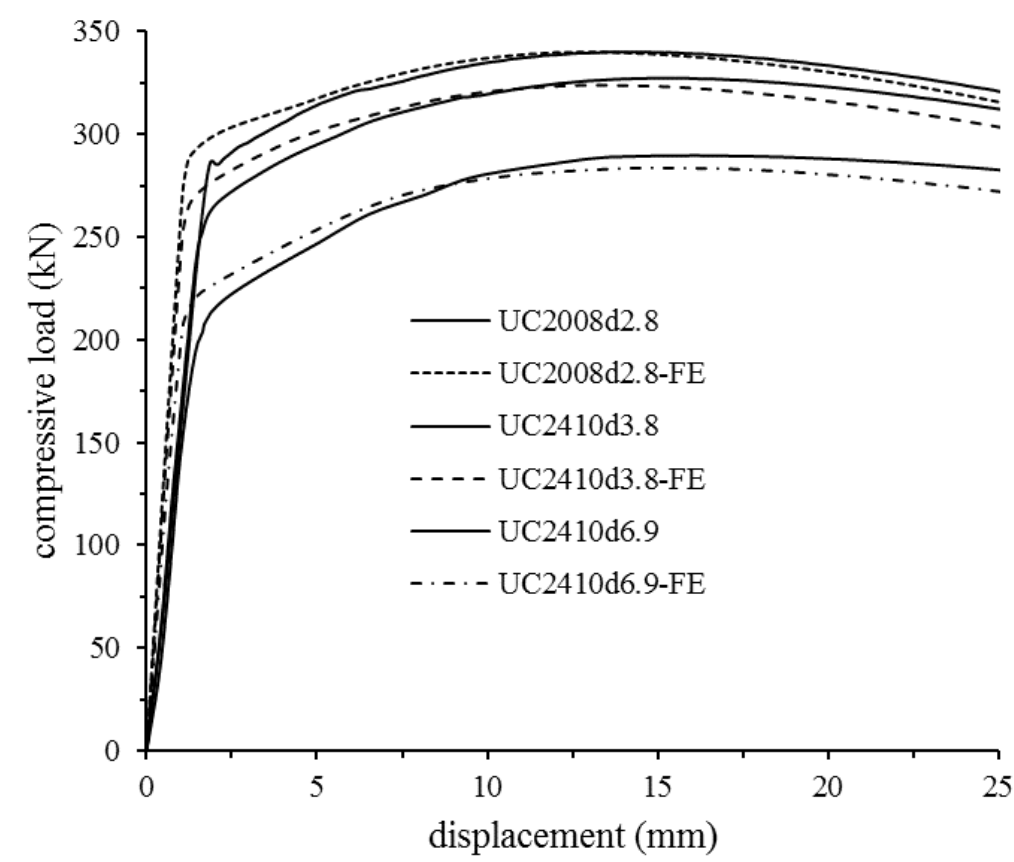

Figure 10 Load shortening curves of typical experimental and corresponding numerical results 

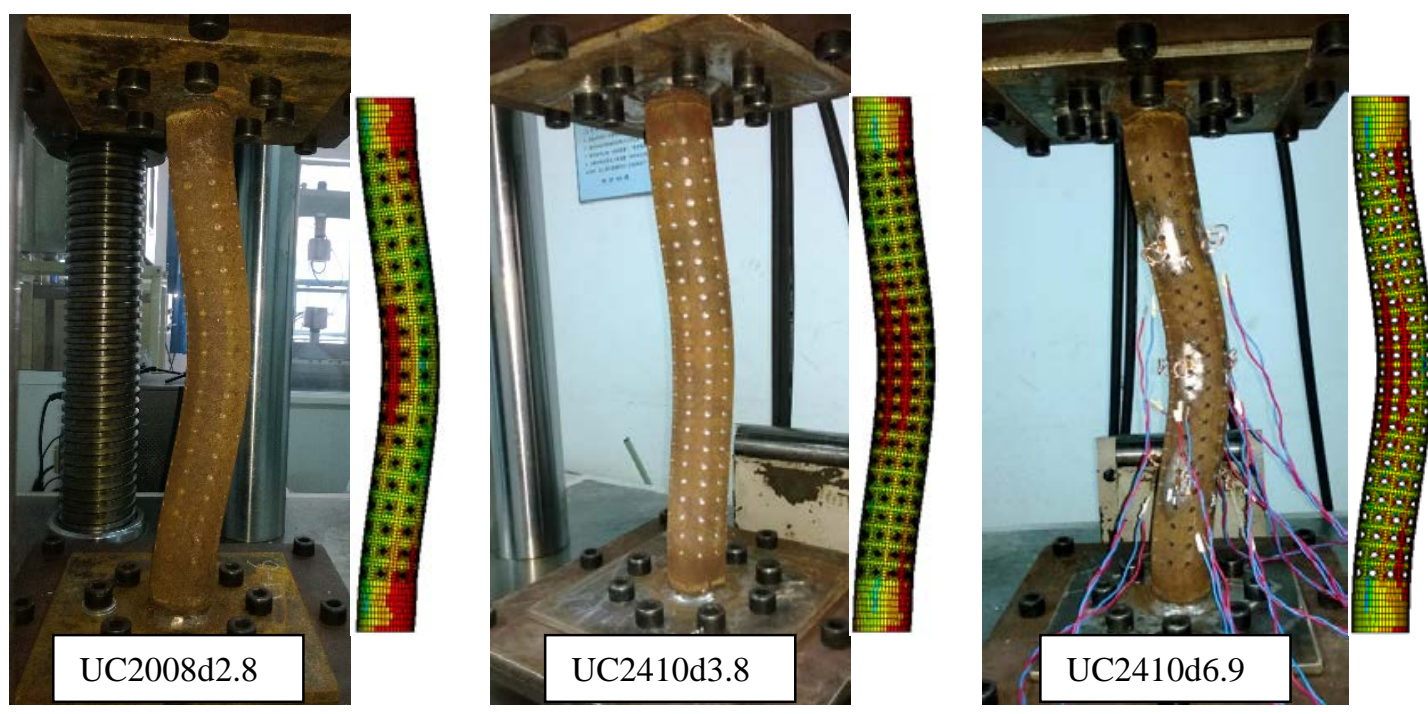

Figure 11 Failure mode of typical experimental and numerical results

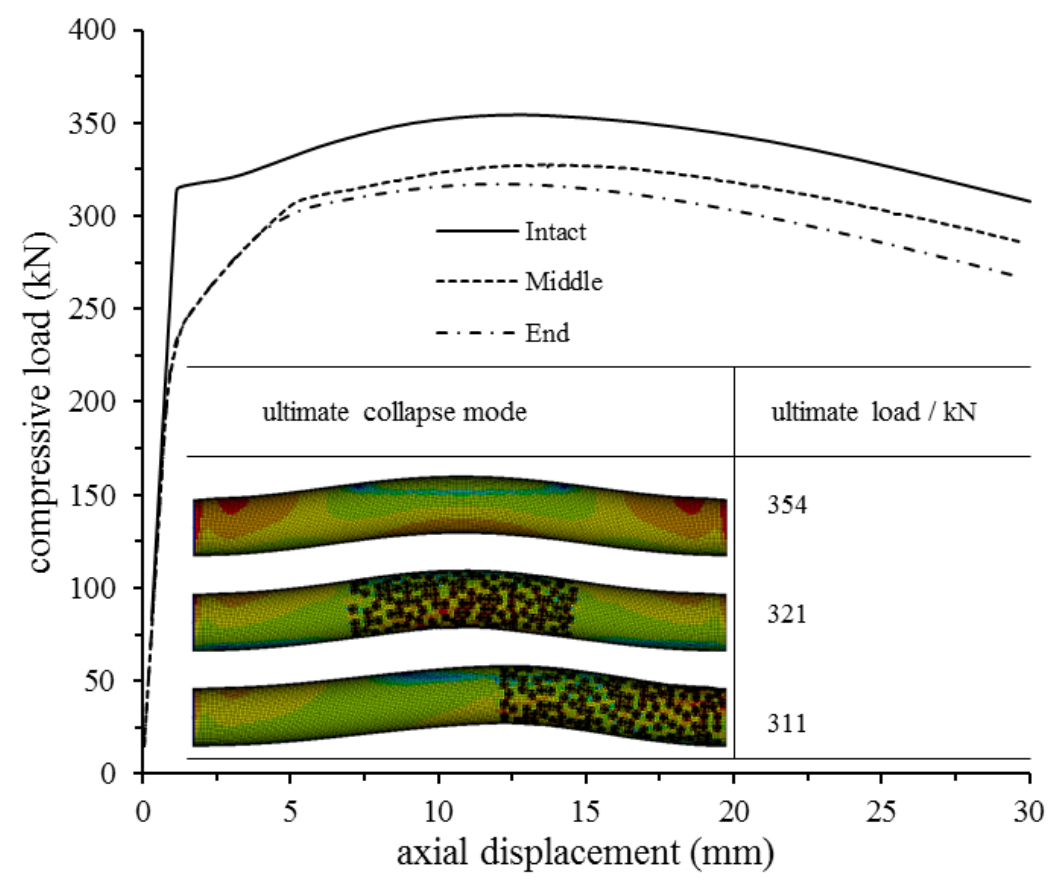

Figure 12 Load shortening curves and collapse modes of tubular members with localized pitting damage 


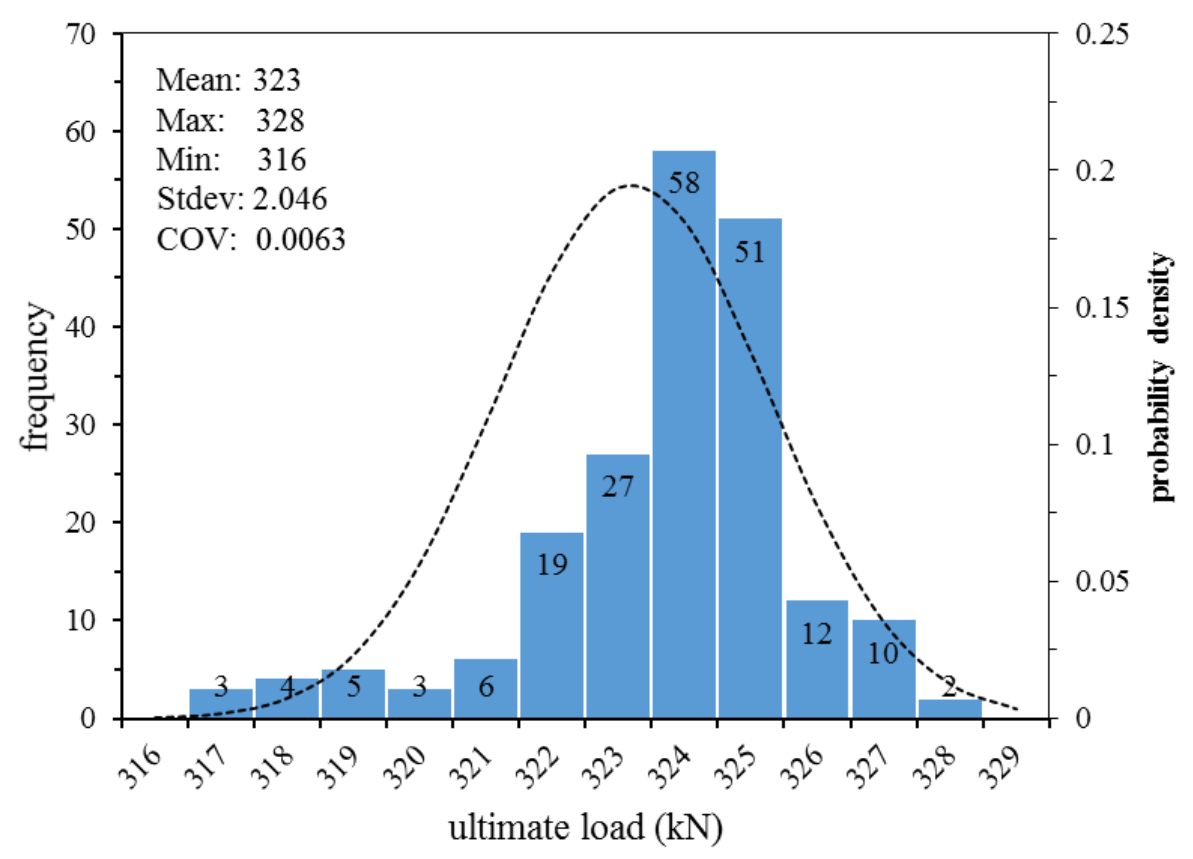

Figure 13 Frequency of ultimate strengths of tubular members subject to measured pitting damage

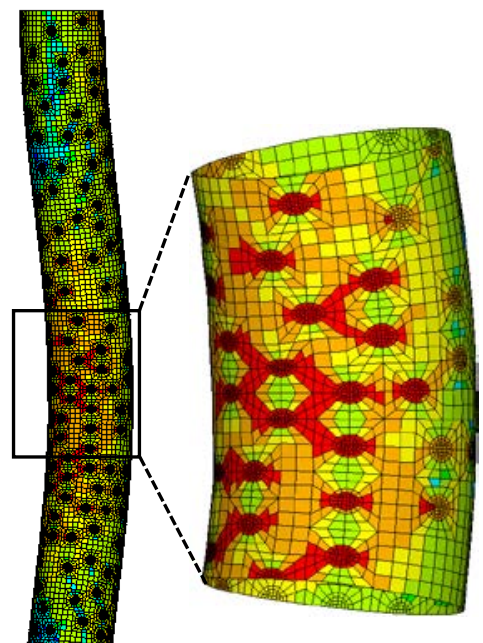

(a)

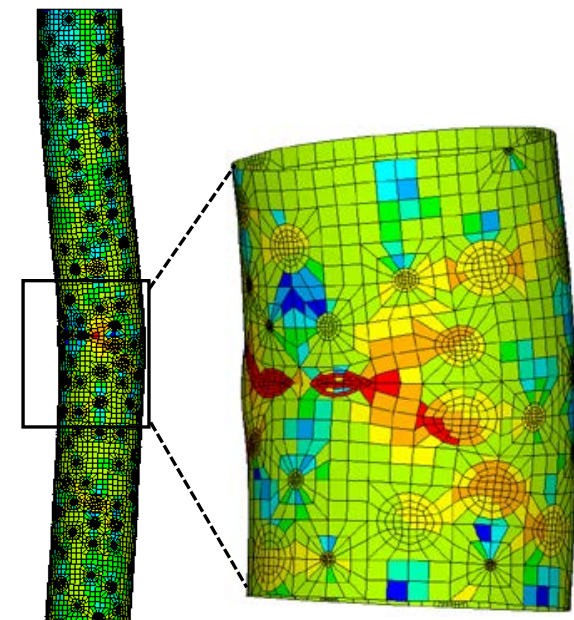

(b)
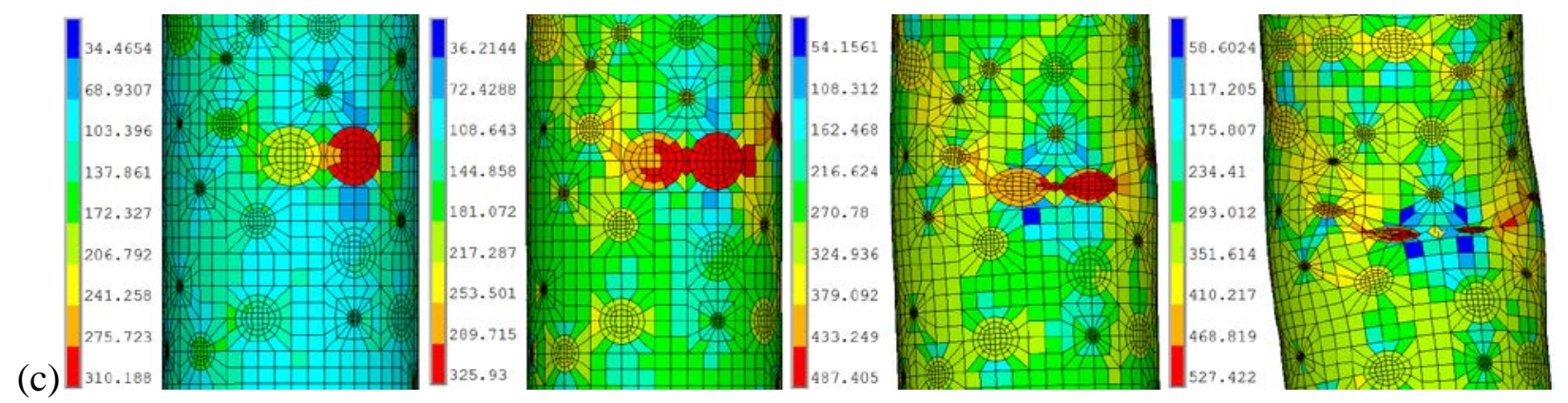

Figure 14 Collapse modes of tubular members subject to pitting damage. (a): measured pitting; (b) random pitting; (c) progress of yielding and local buckling (unit: MPa) 


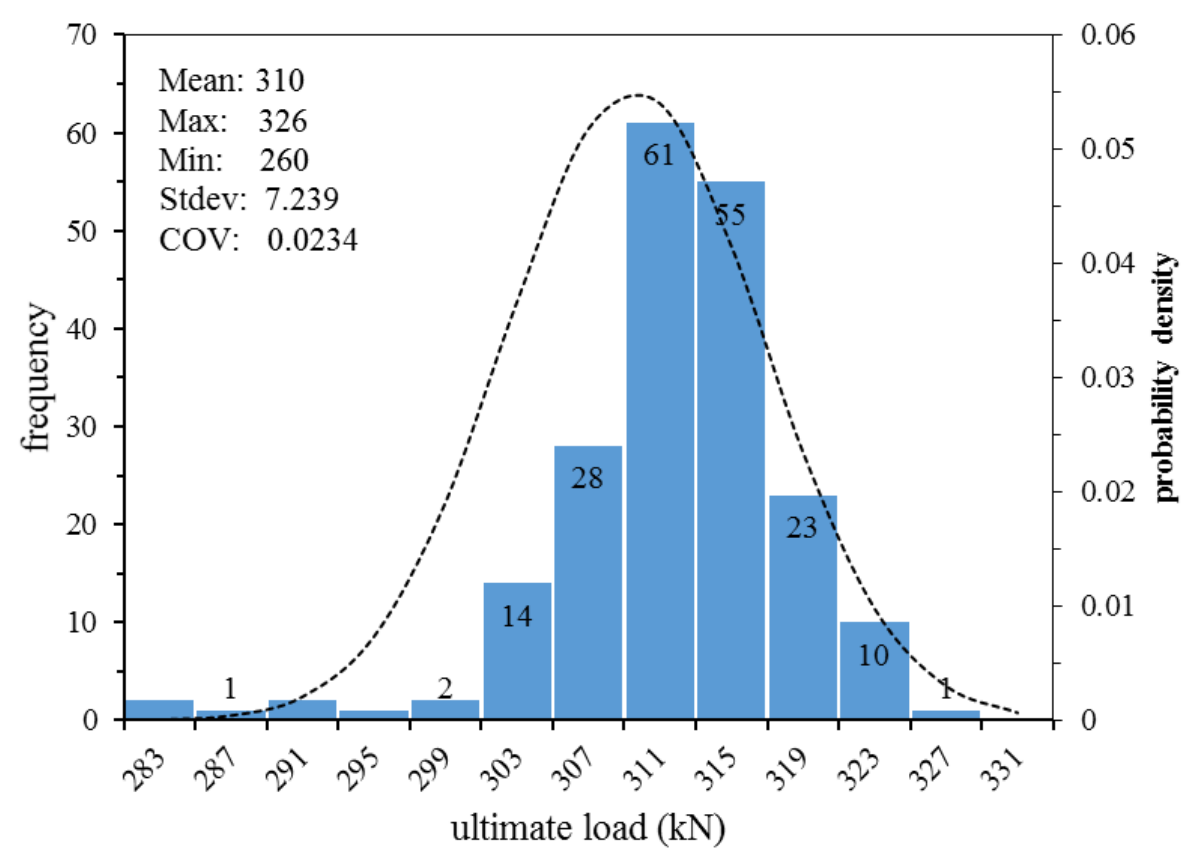

Figure 15 Frequency of ultimate strengths of tubular members subject to random pitting damage

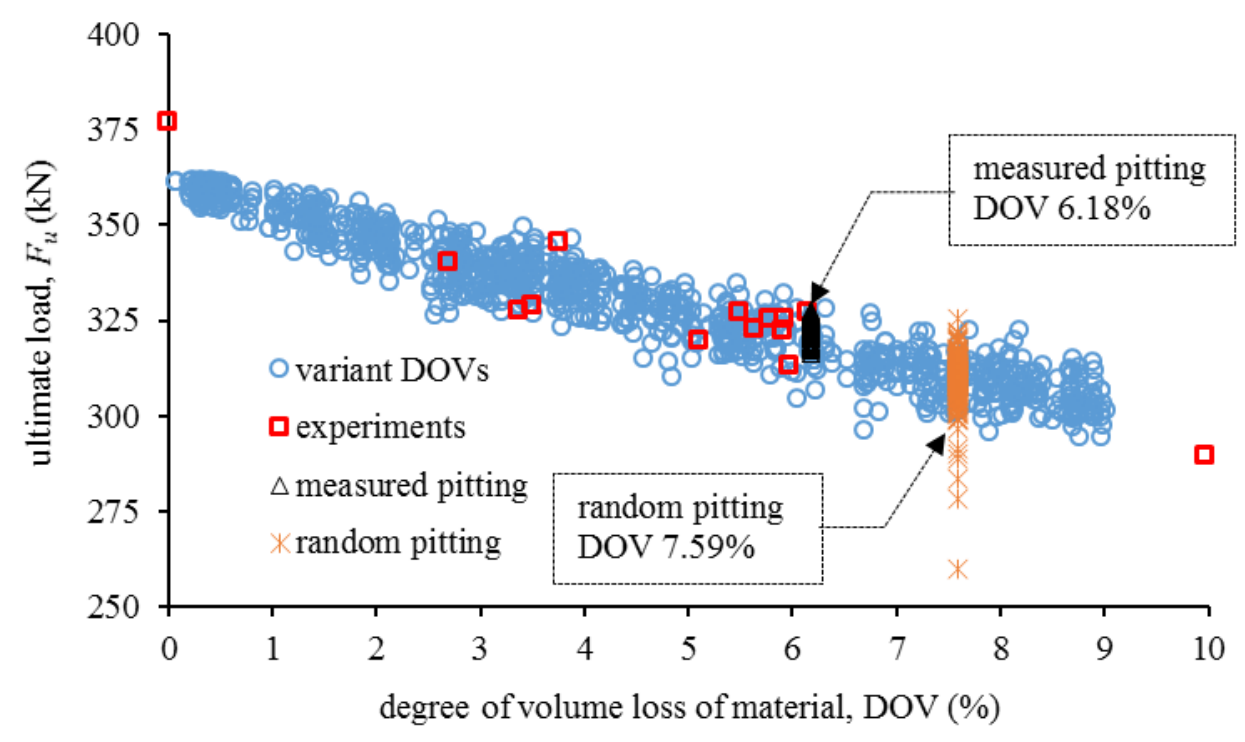

Figure 16 Comparison of ultimate loads between experimental and FE results 


\section{Tables}

Table 1 Pitting damage in tested members

\begin{tabular}{llllllll}
\hline No. & Specimen ID & pit number & distribution & pit shape & $\begin{array}{l}\text { pit depth } \\
(\mathrm{mm})\end{array}$ & $\begin{array}{l}\text { DOP } \\
(\%)\end{array}$ & $\begin{array}{l}\text { DOV } \\
(\%)\end{array}$ \\
\hline 1 & INATCT & - & - & & - & - & - \\
2 & IC2010d4.9 & $20 \times 10$ & interleaved & circular & 4.9 & 8.31 & 5.90 \\
3 & UC2010d4.8 & $20 \times 10$ & uniform & circular & 4.8 & 8.31 & 5.78 \\
4 & UC2008d5.3 & $20 \times 8$ & uniform & circular & 5.3 & 6.65 & 5.11 \\
5 & IC2010d2.9 & $20 \times 10$ & interleaved & circular & 2.9 & 8.31 & 3.49 \\
6 & UC2010d2.8 & $20 \times 10$ & uniform & circular & 2.8 & 8.31 & 3.37 \\
7 & UC2008d2.8 & $20 \times 8$ & uniform & circular & 2.8 & 6.65 & 2.70 \\
8 & IC3010d3.3 & $30 \times 10$ & interleaved & circular & 3.3 & 12.46 & 5.96 \\
9 & UC3010d3.4 & $30 \times 10$ & uniform & circular & 3.4 & 12.46 & 6.14 \\
10 & UC2410d6.9 & $24 \times 10$ & uniform & circular & 6.9 & 9.97 & 9.97 \\
11 & UC2410d3.9 & $24 \times 10$ & uniform & circular & 3.9 & 9.97 & 5.63 \\
12 & UC2410d3.8 & $24 \times 10$ & uniform & circular & 3.8 & 9.97 & 5.49 \\
13 & UP2410d3.6 & $24 \times 10$ & uniform & pyramidal & 3.6 & 9.97 & 3.76 \\
14 & UP2410d5.1 & $24 \times 10$ & uniform & pyramidal & 5.1 & 9.97 & 5.92 \\
\hline
\end{tabular}

Table 2 Summary of experimental results of pitted members

\begin{tabular}{lccccccc}
\hline \multirow{2}{*}{ No. } & \multirow{2}{*}{ Specimen ID } & \multirow{2}{*}{ DOP (\%) } & \multirow{2}{*}{ DOV $(\%)$} & \multicolumn{3}{c}{ Ultimate load } & \multicolumn{3}{c}{ Axial deformation } \\
\cline { 5 - 8 } & & & & $F_{u}(\mathrm{kN})$ & $\delta_{F}(\%)$ & $\Delta_{u}(\mathrm{~mm})$ & $\delta_{\Delta}(\%)$ \\
\hline 1 & INTACT & - & - & 377 & - & 16.378 & - \\
2 & IC2010d4.9 & 8.31 & 5.90 & 323 & 14.4 & 15.385 & 6.1 \\
3 & UC2010d4.8 & 8.31 & 5.78 & 325 & 13.7 & 15.726 & 4.0 \\
4 & UC2008d5.3 & 6.65 & 5.11 & 320 & 15.2 & 16.039 & 2.1 \\
5 & IC2010d2.9 & 8.31 & 3.49 & 329 & 12.8 & 15.553 & 5.0 \\
6 & UC2010d2.8 & 8.31 & 3.37 & 328 & 13.1 & 15.758 & 3.8 \\
7 & UC2008d2.8 & 6.65 & 2.70 & 340 & 9.8 & 14.455 & 11.7 \\
8 & IC3010d3.3 & 12.46 & 5.96 & 313 & 16.9 & 15.83 & 3.3 \\
9 & UC3010d3.4 & 12.46 & 6.14 & 327 & 13.3 & 16.504 & -0.8 \\
10 & UC2410d6.9 & 9.97 & 9.97 & 290 & 23.2 & 16.102 & 1.7 \\
11 & UC2410d3.9 & 9.97 & 5.63 & 323 & 14.3 & 16.794 & -2.5 \\
12 & UC2410d3.8 & 9.97 & 5.49 & 327 & 13.2 & 14.895 & 9.1 \\
13 & UP2410d3.6 & 9.97 & 3.76 & 345 & 8.4 & 15.47 & 5.5 \\
14 & UP2410d5.1 & 9.97 & 5.92 & 325 & 13.7 & 17.174 & -4.9 \\
\hline
\end{tabular}

Notes: the degradation of ultimate load, $\delta_{F}=\left(F_{\text {ref }}-F_{u}\right) / F_{\text {ref }} \times 100(\%)$; and the degradation of deformation, $\delta_{\Delta}=\left(\Delta_{\text {ref }}-\Delta_{u}\right) / \Delta_{\text {ref }} \times 100(\%)$ 
Table 3 Comparison of pitting effect on strength reduction

\begin{tabular}{|c|c|c|c|c|}
\hline Pitting feature & Subgroup & Specimen ID & $F_{u}(\mathrm{kN})$ & $\delta_{F}(\%)$ \\
\hline \multirow[t]{4}{*}{ SHAPE } & \multirow[t]{2}{*}{ A } & UP2410d3.6 & 345 & 8.37 \\
\hline & & UC2410d3.8 & 327 & 13.17 \\
\hline & \multirow[t]{2}{*}{ B } & UC2410d3.9 & 323 & 14.34 \\
\hline & & UP2410d5.1 & 325 & 13.69 \\
\hline \multirow[t]{6}{*}{ DEPTH } & \multirow[t]{2}{*}{ A } & UC2008d2.8 & 340 & 9.78 \\
\hline & & UC2008d5.3 & 320 & 15.22 \\
\hline & \multirow[t]{2}{*}{ B } & UC2010d2.8 & 328 & 13.06 \\
\hline & & UC2010d4.8 & 325 & 13.67 \\
\hline & \multirow[t]{2}{*}{ C } & UC2410d3.9 & 323 & 14.34 \\
\hline & & UC2410d6.9 & 290 & 23.17 \\
\hline \multirow[t]{6}{*}{ DOP } & \multirow[t]{2}{*}{ A } & UC2008d2.8 & 340 & 9.78 \\
\hline & & UC2010d2.8 & 328 & 13.06 \\
\hline & \multirow[t]{2}{*}{ B } & UC2008d5.3 & 320 & 15.22 \\
\hline & & UC2010d4.8 & 325 & 13.67 \\
\hline & \multirow[t]{2}{*}{$\mathrm{C}$} & UC2410d3.8 & 327 & 13.17 \\
\hline & & UC3010d3.4 & 327 & 13.26 \\
\hline \multirow[t]{6}{*}{ PATTERN } & \multirow[t]{2}{*}{ A } & UC2010d2.8 & 328 & 13.06 \\
\hline & & IC2010d2.9 & 329 & 12.79 \\
\hline & \multirow[t]{2}{*}{ B } & UC2010d4.8 & 325 & 13.67 \\
\hline & & IC2010d4.9 & 323 & 14.45 \\
\hline & \multirow[t]{2}{*}{ C } & IC3010d3.3 & 313 & 16.90 \\
\hline & & UC3010d3.4 & 327 & 13.26 \\
\hline
\end{tabular}

Notes: the degradation of ultimate load, $\delta_{F}=\left(F_{\text {ref }}-F_{u}\right) / F_{\text {ref }} \times 100(\%)$ 